\title{
THE ENCYCLOPEDIA OF MUSIC IN CANADA AT 30
}

\author{
BY DESMOND MALEY \\ LAURENTIAN UNIVERSITY
}

As a librarian, I can attest that reference publications like The Encyclopedia of Music in Canada (EMC) are, if anything, all that much more important in the online era. The "born digital" generation, which has little experience with the traditional library, seems disinclined to spend time exploring print collections. ${ }^{1}$ But there is strong interest in the digital versions of such publications, which supply authoritative surveys of subjects as well as departure points for further investigation.

EMC has been provided with open access on the Web by the Historica Foundation (now Historica-Dominion Institute) since 2003, when it was incorporated into The Canadian Encyclopedia (TCE). The not-for-profit institute celebrates the thirtieth anniversary of the publication of the first edition of EMC as it maintains and builds on that original work.

EMC1, published in 1981 and followed by an expanded second edition in 1992, was a landmark event in the annals of Canadian letters. It also sparked considerable attention internationally. The prefaces to both editions, as well as Helmut Kallmann's subsequent articles, remain essential reading for the genesis, editorial philosophy, and reception of this classic.

Perhaps the greatest advantage of the print edition is that one can hold this "tree of knowledge" in one's hands and browse the alphabetical index to discover the variety that may be hidden in today's online version. Care and attention were lavished on the quality of the writing, which made it accessible to a public readership. Despite the small typeface, one can still read it for pleasure. The lexicon is punctuated with well-chosen illustrations and reproductions of photographs that stimulate browsing. Both editions are admirable not only for the quality of their content, but for the directorial organization, indepth index, extensive cross-referencing, and thoroughness and clarity of the documentation.

In contrast, with the online EMC, one tends to see only the "branches." The hopping from branch to branch has made usage more strategic than meditative. For those not accustomed to reading at length on a screen, printing may be required for the longer articles, which the website accommodates with printable versions of all entries. Nevertheless, searchability and the 24/7 universal access are enormous benefits. The online encyclopedia is also a leader in projects funded by the federal Canadian Heritage ministry in that it is the first to have a mobile version. When there is a standard e-reader with wide applicability that includes such features as text searching and note-taking, a downloadable EMC could well be in demand (particularly in the form of a contemporary app) - and reading for pleasure could make a comeback.

1. The pendulum may eventually swing back in terms of the valuation of print collections. There are unresolved issues of access, ownership, preservation, learning styles across the generations, technological change, and close reading in the online era. 
Remarkable progress has been made in updating EMC's entries as well as adding new ones, given the limited funding and small editorial team (six part-time editors). Additions to the encyclopedia include genres previously not covered, or given limited coverage. Photographs, videos and sound files are included, although the video and sound files are often only snippets because of copyright restrictions. All are searchable by media type. Plans are being carried out to embed public video sources within the context of the articles. Full-text searching by keyword is easy and there is a subject index for those who like to browse. Articles are hyperlinked to related content within EMC and most contain links to related sites such as the Canadian Music Centre, the home pages of individuals and organizations, and videos from YouTube. All external links are vetted for authority and suitability for classroom use.

Updating and expanding content is a priority. Certainly articles have no lack of readers. According to Editor-in-Chief James Marsh, who oversees both the online The Canadian Encyclopedia and The Encyclopedia of Music in Canada, the site had 505,000 unique visitors during the month of September 2011. Of these, approximately 100,000 went to EMC, vastly more people than have had access to, or read, the print editions. Given the increased emphasis on the measurement of scholarly activity, academic contributors can not only note that they are writing for Canada's premiere e-reference on music, they could also point to the number of visits the pages are drawing.

The institute contracts out to have its site usage analyzed on a monthly basis. Visits to the EMC pages for university music programs are particularly frequent. The institute also tries to keep pace with hot topics such as pop phenom Justin Bieber. But it also remains responsible to its mandate to be comprehensive and inclusive, and less-visited entries are no less important in terms of offering a website of encyclopedic scope and breadth.

The impetus to develop a digital EMC dates to the late 1990s. On the initiative of $S$. Timothy Maloney, who was then Director of the National Library of Canada's Music Division, the EMC Board and the University of Toronto Press authorized digitization of EMC2 as a National Library project. A text-only version was mounted in 2001 using database software developed by the National Library's information technology staff. EMC2 may still be viewed on the Library and Archives Canada website, although there is a message on the home page that directs visitors to the Historica-Dominion site.

There were efforts to publish a third print edition of EMC. Canada Council grants were obtained to hire a contract researcher-writer, and Maloney volunteered to edit approximately 200 of the articles that were subsequently written. Proposals were also made to the Heritage ministry. Funding, however, was not forthcoming, and this time there was no Floyd Chalmers, the benefactor to whom both print editions were dedicated.

Maloney, who by this point was EMC Board Chair, worked with James Marsh and the Historica Foundation to obtain funding from the ministry to incorporate the full content of EMC into the TCE website. The application was successful, whereupon the EMC Board dissolved and all of the rights were given to Historica (in 2009, Historica merged with the Dominion Institute to create the Historica-Dominion Institute). The institute, through 
TCE, assumed responsibility for EMC under the editorship of Marsh with associate editor Laura Bonikowsky and a small but dedicated team.

Given the fluid nature of websites, when can it be said that a new edition of EMC really emerged? A touchstone would be the revision of the major articles as well as new material on the twenty-first century musical landscape. One need look no farther than the pages of CAML Review to see how much Canada's musical culture has evolved over the past twenty years - highlighted, for example, in Patricia Debly's impressive survey of the shifting currents of musicology, ${ }^{2}$ or in the $C D$ and book reviews on a rising generation of composers and performers.

One theme, however, does remain a constant. It is incumbent upon Canadians to tell the story in all of its complexity and variety. That was true in 1981, and it remains no less true today. Occasionally there are worthwhile contributions from the international sphere, but nothing can match EMC for its comprehensiveness and richness. Let us hope that scholars, musicians, composers, librarians, teachers, journalists and other interested parties will take up the torch both in terms of providing content and ensuring that funding continues to be available for this important national resource.

\section{WORKS CONSULTED}

The author gratefully acknowledges email correspondence and/or telephone interviews with Laura Bonikowsky, Sarah Church, Florence Hayes, S. Timothy Maloney, and James Marsh.

Beckwith, John. Music Papers: Articles and Talks by a Canadian Composer, 19611994. Ottawa: Golden Dog, 1997.

Kallmann, Helmut. "The Making of a One-Country Music Encyclopedia: An Essay after an Encyclopedia." Fontes Artis Musicae 41, no. 1 (1994): 3-19.

. "Mapping Canada's Music: A Life's Task." In Music in Canada / La Musique au Canada: A Collection of Essays, v. 1, edited by Guido Bimberg, 11-34. Bochum: Universitätsverlag Dr. Norbert Brockmeyer, 1997.

Kallmann, Helmut, and Gilles Potvin. "Preface." In Encyclopedia of Music in Canada, 2nd ed., edited by Helmut Kallmann and Gilles Potvin, xv-xvi. Toronto: University of Toronto Press, 1992.

Kallmann, Helmut, Gilles Potvin, and Kenneth Winters. "Introduction." In Encyclopedia of Music in Canada, xi-xiv. Toronto: University of Toronto Press, 1981.

2. Patricia Debly, "Pirates, Humpty Dumpty and a Brazilian Bishop: The Myth of Musicology," CAML Review 29, no. 2 (2001): 33-40. 